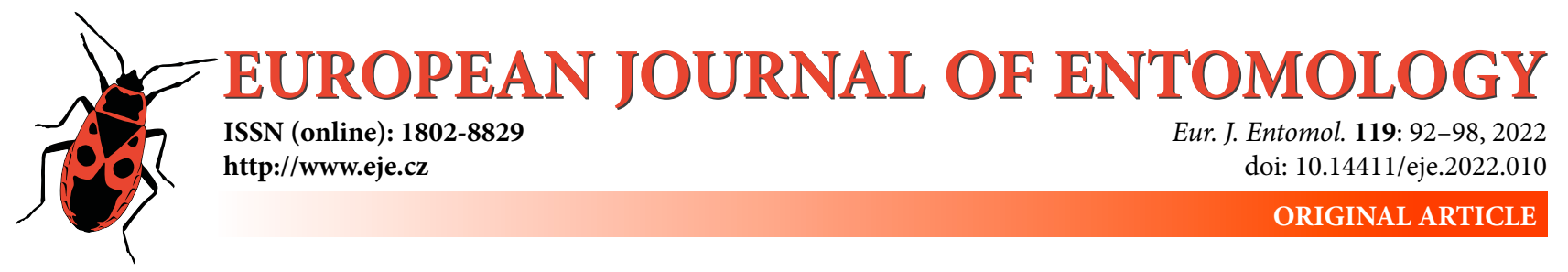

\title{
Biogeography and habitat preferences of red wood ants of the Formica rufa group (Hymenoptera: Formicidae) in Finland, based on citizen science data
}

\author{
JouNI SORVARI ${ }^{1,2}$ (D) \\ ${ }^{1}$ Department of Biology, University of Turku, FI-20014 Turku, Finland; e-mail: jouni.sorvari@utu.fi \\ ${ }^{2}$ Natural Resources Institute Finland (Luke), P.O. Box 2, FI-00790 Helsinki, Finland; e-mail: jouni.sorvari@luke.fi
}

Key words. Crowd sourcing, latitude gradient

\begin{abstract}
Red wood ants (RWA) of the Formica rufa group are ecosystem engineers and important species in boreal and temperate forests. However, the permanent and temporal loss of forest habitats is a serious threat to their existence and is likely to increase with climate change. Due to the current threat of losing species, quick actions are needed. Reported here is the biogeography, relative abundance and habitat preferences of five species of RWA in Finland based on citizen science data. Species that occur in the lowlands of the Alps also occur throughout the southern parts of Finland. Only two of the five species, $F$. aquilonia Yarrow, 1955 and F. lugubris Zetterstedt, 1838, were common throughout the country, including northern Lapland. As their name suggests, RWAs occur mostly in forests and forest edges, but they also sometimes inhabit open or semi-open yards, mires and meadows. The most forest-specialist species is $F$. aquilonia and the least $F$. rufa Linnaeus, 1761 . Surprisingly, the meadow wood ant $F$. pratensis Retzius, 1783 is the second most forest dwelling species, however, its preference for forest edges is clearly higher than for forest interiors. Based on current data, F. rufa may be the most tolerant of living close to buildings as its relative abundance in yards was much higher than that of the other species. The data obtained on distributions and relative abundances could be compared in the future with the results of similar surveys to detect changes in species distributions, relative abundances and habitat preferences.
\end{abstract}

\section{INTRODUCTION}

The red wood ants of F. rufa group (RWA) are ecosystem engineers as they change their habitat by collecting organic nest material and altering soil properties (Frouz et al., 2016). However, the species may vary in their potential role as ecosystem engineers due to their different nesting habitats and colony sizes. RWAs have wide multi-trophic interactions as they are predators of many insects, mutualists with aphids and are food for many arthropods, birds and vertebrates (e.g., Domisch et al., 2016; Robinson et al., 2016). In addition, RWAs are important umbrella species since their nests are habitats for a vast number of insects and other arthropods (Robinson et al., 2016); thus, RWAs and their nest mounds should be considered in biodiversity conservation programmes.

The major threat to this species group is loss of habitat (Social Insects Specialist Group, 1996) - in the RWAs' case, woodland. All five RWA species studied here are globally near threatened (NT), but they are still common and unprotected by law in Finland (nationally classified as least concern, LC; Paukkunen et al., 2019). Forest cover is decreasing due to urban sprawl, agriculture and the wood industry. Forest clear-cutting is the main forest renewal method in Finland (Vaahtera, 2019). Clear-cut areas are planted with new, usually a monoculture of seedlings; thus, the habitat loss is partly temporal. But as new forest in Finland is typically a monoculture of Norway spruce (Picea abies) or Scots pine (Pinus sylvestris), this form of forest management also changes the configuration of forests. Clear-cutting has resulted in severe harm to local RWAs as the main source of food, canopy-dwelling aphids and their excreta and prey arthropods (hunting mainly in trees; see Lenoir, 2003), are lost with logging. In addition, the changed microclimate adversely affects the thermoregulation of RWA mounds that are built for a shaded forest environment (Sorvari et al., 2016). As a result of the dramatic habitat change, local populations decrease rapidly after logging (Sorvari \& Hakkarainen, 2007).

The current trend of climate warming presents an additional synergetic challenge to RWAs, especially those that are locally adapted to northern conditions. For RWAs, prolonged drought may be harmful, but this has not yet been studied. The effect of higher overwintering temperatures has been shown to increase the wintertime mortality of workers. This effect was almost two-fold for colonies that 
have recently experienced forest clear-cutting (Sorvari et al., 2011).

There are two different concepts for the Formica rufa species group. The European literature mainly refers to a part of the species belonging to the sub-genus Formica s.str., while the North American literature replaces the sub-genus by including it in the Formica rufa group. Here, the Formica rufa group is treated in the European way by limiting the group members to the closely related group of dome-shaped mound-building Formica ants of Formica s.str., leaving out F. truncorum (Fabricius, 1804) and F. frontalis (Santschi, 1919), which mostly build irregular and flat mounds. In addition, the phylogenetic position of these species is more distant (Goropashnaya et al., 2004; however, see Goropashnaya et al., 2012). This F. rufa group consists of eight species in Europe, of which five occur in Finland (Finnish species listed in Table 1).

The black-backed meadow ant Formica pratensis Retzius, 1783 is sometimes not listed as a member of the Formica rufa group due to its difference in colouration and habitat preference compared to other members of the group (Yarrow, 1955; Dlussky, 1967; Czechowski, 1996). However, it shares the same morphological characters, e.g., that of antennal funiculus morphometrics (Czechowski et al., 2012) and based on molecular data shown to be grouped with the $F$. aquilonia- $F$. paralugubris-F. lugubris-complex and more distantly to the $F$. rufa- $F$. polyctena-complex (Goropashnaya et al., 2004, 2012). Thus, it should be treated as a member of the European Formica rufa group.

In mountainous areas different RWAs can have altitudinal limits in their distribution (e.g., Vandegehuchte et al., 2017; Seifert, 2018; Antonova \& Marinov, 2021). For example, in the Alps in Central Europe, the species of the $F$. rufa group can be divided into lowland species and highland species (Table 1). In Finland, the altitude gradient is not that clear, especially because generally the altitude slowly increases with increase in latitude. For example, $F$. aquilonia is common throughout the country, thus the altitude-based distribution pattern is strongly affected by the northern location of Finland. Therefore, in Finland, instead of altitude gradients, it is more practical to use zones that roughly represent the south-north gradient (e.g., Punttila \& Kilpeläinen, 2009). Formica polyctena is a lowland species in Central Europe and is a common species in southern Finland, but it is also found in northern Finland (Punttila \& Kilpeläinen, 2009; Sorvari, 2021).

Of the species, the Finnish populations of F. rufa, F. lugubris and $F$. pratensis have mainly single nest colonies, whereas $F$. aquilonia and $F$. polyctena have almost always multiple nest colonies (monodomy and polydomy, respectively) (Rosengren \& Pamilo, 1983). Therefore, while this is a population level phenomenon (Rosengren \& Pamilo, 1983), for simplicity they are hence forth called monodomous and polydomous species. The monodomous species tend to have either only one or very few (monogyny or oligogyny) reproducing queens in their nests, whereas the polydomous species can have hundreds of functional queens (polygyny) per nest and dozens of nests per poly-
Table 1. The Finnish members of the Formica rufa group, their approximate altitudinal preferences (metres above sea level) in the Alps, Central Europe (Seifert, 2018) and distribution in Finland (Collingwood, 1979; Punttila \& Kilpeläinen, 2009).

\begin{tabular}{|c|c|c|}
\hline Species & Altitude Alps & $\begin{array}{c}\text { Distribution } \\
\text { in Finland }\end{array}$ \\
\hline ormica rufa Linnaeus, 1761 & $<1500 \mathrm{~m}$ & Southern \\
\hline Formica polyctena Förster, 1850 & $<1200 \mathrm{~m}$ at least & $?$ \\
\hline Formica pratensis Retzius, 1783 & & Southern \\
\hline & & Whole country \\
\hline Formica lugubris Zetterstedt, 1838 & $550-2510 \mathrm{~m}$ & Whole country \\
\hline
\end{tabular}

domous colony (Rosengren \& Pamilo, 1983). Due to the limited life span of a queen, monogynous colonies do not live for decades as the polygynous nests do. Thus, the nests of F. rufa, F. lugubris and F. pratensis tend to be smaller than that of $F$. aquilonia and $F$. polyctena, although young nests of the two latter species are initially small (e.g., Punttile \& Kilpeläinen, 2009).

Punttila \& Kilpeläinen (2009) report preliminary results of a mound-building Formica ant survey carried out during the $10^{\text {th }}$ Finnish national forest inventory survey (NFI10) in 2005-2008. However, northern Lapland was not included in the NFI10 survey, thus missing valuable ant data from an area where conifer growth is limited and the landscape includes many sub-arctic fjelds (relatively low, rounded mountains). The NFI10 data was collected from forested woodland and mire habitats, leaving out more open or urban habitats like roadsides, meadows and yards, etc., which are often poorly surveyed and possibly suboptimal habitats of wood ants.

Although forest is often mentioned as the habitat for RWAs, the species are not identical in their habitat requirements, e.g., they may have differences in tolerance to canopy closure or may even occur mainly outside forests (e.g., Punttila \& Kilpeläinen, 2009; Czechowski et al., 2012; Vandegehuchte et al., 2017; Antonova \& Marinov, 2021). In Finland, F aquilonia and F. polyctena are often reported nesting in the interiors of forests as well as their margins, whereas F. rufa, F. lugubris and F. pratensis are dwellers of forest edges or young successional stage forests (Punttila, 1996). This however, is not fully confirmed since observations for F. rufa, F. polyctena and F. pratensis were too scarce for inclusion in the analysis of the large census of Punttila \& Kilpeläinen (2009). This could be due to the forest-oriented sampling grids; thus, it would be important to survey additional habitats, such as meadows and yards around houses (backyards, gardens, etc.). However, it is difficult for researchers to intrude into the vicinities of houses without asking permissions from each inhabitant.

Recently citizen science-based distribution records of Finnish RWAs and other mound building Formica ants were published (Sorvari, 2021), which show the distributions of these species. However, the maps do not quantitatively show the relative abundance of species along a latitudinal gradient, i.e., percentage of each species in all samples collected in a certain latitude zone. In addition, the survey data included valuable habitat information on 
forests and built up areas that is not published in basic distribution records.

Due to the apparent and serious threat (and possible changes in the ranges of species), it is essential to update our knowledge on the biogeography and habitat preferences of RWAs in Finland and preferably in the near future in other countries as well. Already there are significant censuses for some European countries, e.g., Switzerland and Bulgaria (Vandegehuchte et al., 2017; Antonova \& Marinov, 2021) that provide a good basis for among country comparisons over wide geographical area.

My goal here was to study the (1) relative abundances of species in different latitudinal zones and (2) habitat preference of the F. rufa group red wood ants in Finland.

\section{MATERIAL AND METHODS}

The data was collected in the summer of 2018 and 2019 using the citizen science project, 'Wood ant survey of Finland - citizens making science'. The survey updated the distribution and habitat preferences of Formica s.str., Coptoformica, Raptiformica and Formica uralensis in Finland (see Sorvari, 2021). The project resulted in 2434 samples, of which 2089 were for members of the Formica rufa group.

Two of the Formica rufa group samples were not possible to identify at the species level because they were visually intermediate between $F$. aquilonia and $F$. polyctena. These were probably hybrids between those species as their hybridization is reported occurring in Finland (Czechowski, 1996; Sorvari, 2006; Kulmuni et al., 2010). The two possible hybrids were sampled from the southern part of Finland (South 1 and South 2 zones; see zone descriptions below). These two samples were omitted from the analysis, which included 2087 nest samples (see map, Fig. 1).

The citizen collectors gave the location of the sample either using coordinates or by a street address or reference to a specific location in the landscape, resulting in a relatively accurate geographic location. The possible error in the locations not based on coordinates is $2.5 \mathrm{~km}$ at most, but usually less than $200 \mathrm{~m}$. One F. polyctena sample had no geographic or habitat information, so it was omitted from all analyses. The collectors also categorized the nesting habitat as forest, forest edge, open yard of houses, meadow or mire. Yards around Finnish houses are typically semiopen fields with scattered single trees.

All coordinates and locations were transformed into ETRSTM35FIN coordinates, which directly allows distance measurements on a metric scale. The difference between the most southern and most northern N-coordinate in continental Finland is $1139.232 \mathrm{~km}$. In order to study the relative abundance along a latitudinal gradient, the total length of Finland was divided into five zones of $227.846 \mathrm{~km}$. The zones were named South 1 (ETRS $\mathrm{N}$ : 6637094-6864940), South 2 (6864940-7092787), Middle (7092787-7320633), North 1 (7320633-7548480) and North 2 (7548480-7776326) (Fig. 1). None of the samples were collected from the borders between zones. The numbers of samples differed between zones. Thus, the abundance of each species was related to the sampling effort per zone, i.e., the percentage of all samples from a zone with a particular species: the 'relative abundance'.

The relative abundance of species in the latitudinal zones and habitat preferences were compared using likelihood-ratio chisquare tests $\left(G^{2}\right)$. Additional comparisons were also made between ecologically similar species, i.e., polydomous $F$. aquilonia and $F$. polyctena as well as monodomous $F$. rufa, F. lugubris and F. pratensis. Statistical analyses were carried out using SAS 9.4 statistical software (SAS Inc., Cary, IL, USA).

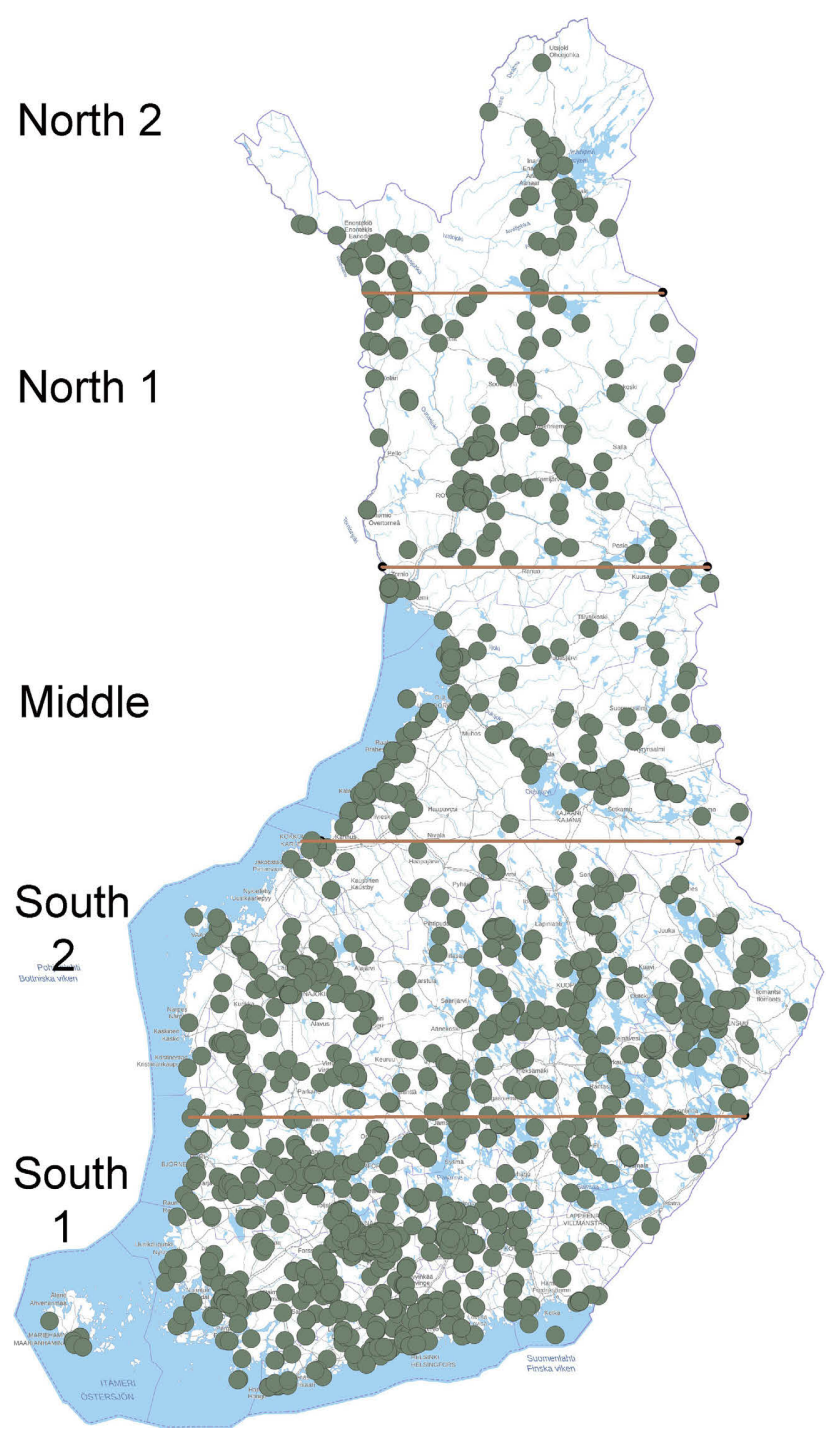

Fig. 1. Distribution of the locations of the wood ant citizen science records and the boundaries of the five latitudinal zones in Finland.

\section{RESULTS}

\section{Distribution and abundance}

Two of the species, F. rufa and F. pratensis, were clearly southern in their distribution, being absent in zones North 1 and North 2 (Table 2). The rest of the species, F. aquilonia, $F$. lugubris and F. polyctena, were found in all five zones. However, only very few samples of $F$. polyctena were reported in the three northernmost zones, indicating only a scattered distribution in the north (Table 2).

In all zones, $F$. aquilonia was by far the most common species and $F$. pratensis the rarest (Table 2$)$. The relative abundance of species varied across zones $\left(G^{2}=439.73\right.$, $\mathrm{df}=16, \mathrm{p}<0.0001$; Fig. 2). The relative abundances of the polydomous species pair $F$. aquilonia and $F$. polyctena across the zones differed significantly as the relative abundance of $F$. aquilonia compared to $F$. polyctena was higher in all zones, being almost $100 \%$ in the three northernmost zones $\left(G^{2}=196.87\right.$, df $=4, \mathrm{p}<0.0001$; Fig. 3A). Among the monodomous species, F. lugubris, F. rufa and F. pratensis, the relative abundance differed significantly as the 


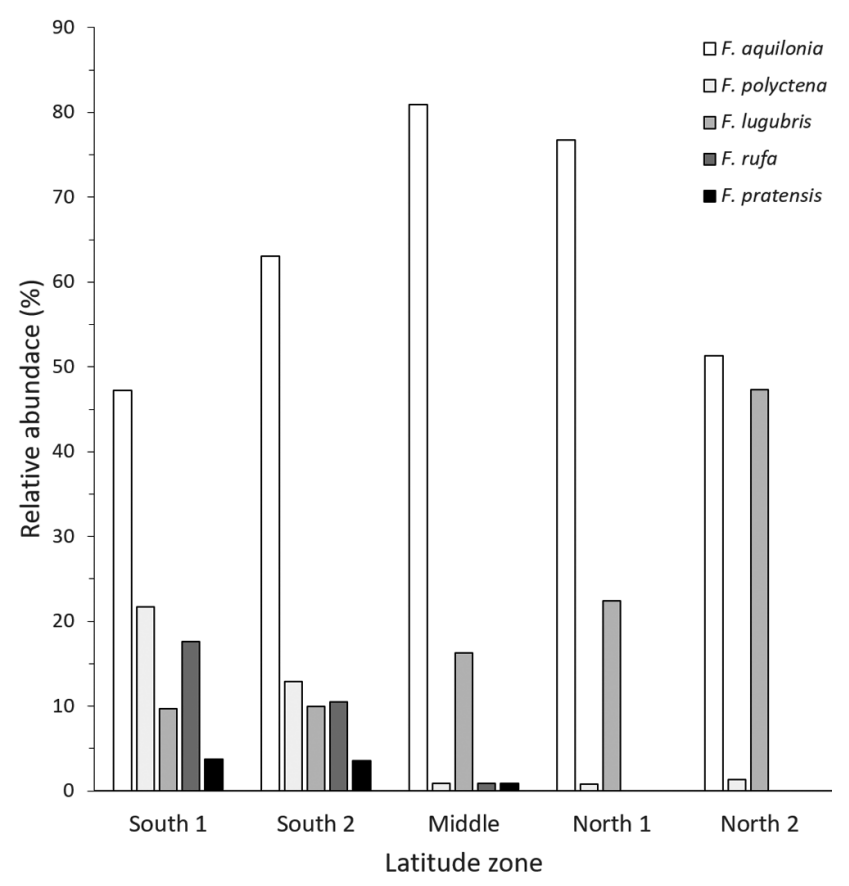

Fig. 2. Relative abundances of the five species of wood ants in the five latitudinal zones studied in Finland.

relative abundance of $F$. lugubris dominated the three northernmost zones, being $100 \%$ in North 1 and North 2 $\left(G^{2}=206.59, \mathrm{df}=8, \mathrm{p}<0.0001\right.$; Fig. 3B $)$.

\section{Habitat preference}

All five species were present in all five classes of habitat (Table 3). Of the 2087 samples, 18 had no information on the habitat and were omitted from further analyses. The preferred habitat differed between species $\left(G^{2}=104.18\right.$, df $=16, \mathrm{p}<0.0001$; Table 3). Preference for forest interiors was highest in F. aquilonia and lowest in F. rufa, whereas that for forest edges was highest in F. pratensis and lowest in $F$. aquilonia. Preference for yards was surprisingly high for F. rufa $(15.2 \%)$. Meadows and mires were not highly preferred by wood ants. However, among the species, $F$. pratensis and $F$. rufa were relatively most abundant in meadows and $F$. lugubris in mires.

The habitat preferences of the polydomous species pair, $F$. aquilonia and $F$. polyctena, did not differ $\left(G^{2}=5.05\right.$, $\mathrm{df}=4, \mathrm{p}=0.28$ ). Comparing the three monodomous species, forests and mires were most common habitats for $F$. lugubris, forest edges for F. pratensis and yards for F. rufa.

Table 2. Numbers of nests of species of the F. rufa group in five latitudinal zones recorded by citizens in Finland 2018-2019. Main type of colony of the species (Type) $\mathrm{P}$ - polydomy, $\mathrm{M}$ - monodomy. Total numbers of each species are shown along with the relative abundance of each species in wood ant samples (\% in parenthesis).

\begin{tabular}{|c|c|c|c|c|c|c|c|}
\hline Species & Type & South 1 & 1 South 2 & Middle & North 1 & North 2 & Total (\%) \\
\hline F. aquilonia & $\mathrm{P}$ & 495 & 317 & 174 & 188 & 38 & $1212(58.1)$ \\
\hline F. polyctena & $P$ & 228 & 65 & 2 & 2 & 1 & $298(14.3)$ \\
\hline F. lugubris & $M$ & 102 & 50 & 35 & 55 & 35 & $277(13.3)$ \\
\hline F. rufa & M & 185 & 53 & 2 & 0 & 0 & $240(11.5)$ \\
\hline F. pratensis & M & 39 & 18 & 2 & 0 & 0 & $59(2.8)$ \\
\hline Total N & & 1049 & 503 & 215 & 245 & 74 & 2086 \\
\hline
\end{tabular}
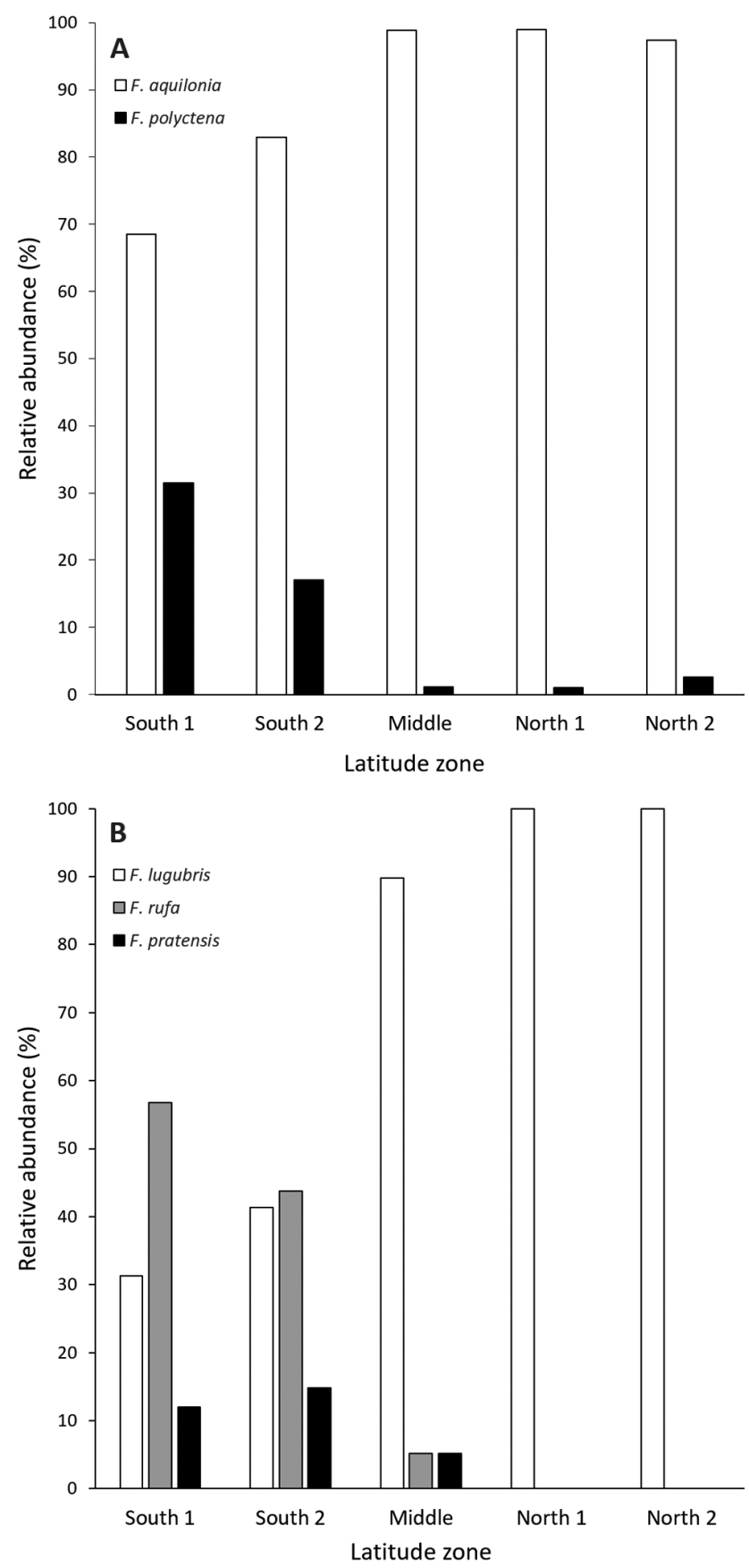

Fig. 3. Zone-wise relative abundances of $(A)$ the polydomous species Formica aquilonia and F. polyctena and (B) the monodomous species F. lugubris, F. rufa and F. pratensis.

Meadows were a less common habitat for F. lugubris than for F. pratensis and F. rufa. Habitat preference differed significantly among the monodomous species $\left(G^{2}=34.38\right.$, df $=8, \mathrm{p}<0.0001$; Table 3 ).

Table 4 shows the number of citizen science records (nests) for the Formica rufa group of wood ants in different habitats in the five latitudinal zones. Habitat preferences for $F$. aquilonia, but not $F$. lugubris, differed for all five zones ( $F$. aquilonia: $G^{2}=41.99$, df $=16, \mathrm{p}=0.0004 ; F$. lugubris: $\left.G^{2}=21.69, \mathrm{df}=16, \mathrm{p}=0.15\right)$. The other three species: F. polyctena, F. rufa and F. pratensis, were almost absent outside the South 1 and South 2 zones (see Tables 
Table 3. Numbers of samples recorded by citizens in different habitats. The percentage in parenthesis is the relative preference for each habitat by each species.

\begin{tabular}{lcccccc}
\hline Species & Forest & Forest edge & Yard & Meadow & Mire & Not known \\
\hline F. aquilonia & $585(48.6 \%)$ & $527(43.8 \%)$ & $73(6.1 \%)$ & $13(1.1 \%)$ & $6(0.5 \%)$ & 8 \\
F. polyctena & $125(42.7 \%)$ & $136(46.4 \%)$ & $25(8.5 \%)$ & $5(1.7 \%)$ & $2(0.7 \%)$ & 6 \\
F. lugubris & $94(34.1 \%)$ & $153(55.4 \%)$ & $14(5.1 \%)$ & $4(1.4 \%)$ & $11(4.0 \%)$ & 1 \\
F. rufa & $61(25.7 \%)$ & $127(53.6 \%)$ & $36(15.2 \%)$ & $12(5.1 \%)$ & $1(0.4 \%)$ & 3 \\
F. pratensis & $17(29.3 \%)$ & $35(60.3 \%)$ & $2(3.4 \%)$ & $3(5.2 \%)$ & $1(1.7 \%)$ & 1 \\
\hline
\end{tabular}

2 and 3). Thus, their habitat preference was compared statistically only between the South 1 and South 2 zones. All three species showed similar habitat preferences in these two zones $\left(F\right.$. polyctena: $G^{2}=8.75, \mathrm{df}=4, \mathrm{p}=0.068 ; F$. rufa: $G^{2}=6.26, \mathrm{df}=4, \mathrm{p}=0.18 ; F$. pratensis: $G^{2}=3.95, \mathrm{df}$ $=4, \mathrm{P}=0.41)$. The only species that differed statistically between zones was $F$. aquilonia, and the major differences seem to be between Forest and Forest edge habitats. The preference for forest edges seems to be higher than that for forest interiors at the central latitudes, South 2 and Middle (Table 4). The most northern zone, North 2, had clearly fewer records compared to other zones and thus possibly lacks records from yards, meadows and mires.

\section{DISCUSSION}

\section{Distribution and abundance}

Based on the distributions and abundances of the species in the latitudinal zones used, the species can be classed

Table 4. Number of citizen science records (nests) of the Formica rufa group wood ants in different habitats in the five latitudinal zones. 'Edge' is forest edge.

\begin{tabular}{lccccc}
\hline F. aquilonia & Forest & Edge & Yard & Meadow & Mire \\
\hline South 1 & 270 & 197 & 23 & 3 & 1 \\
South 2 & 134 & 149 & 23 & 7 & 1 \\
Middle & 61 & 90 & 18 & 1 & 2 \\
North 1 & 96 & 77 & 9 & 2 & 2 \\
North 2 & 24 & 14 & 0 & 0 & 0 \\
\hline F. polyctena & Forest & Edge & Yard & Meadow & Mire \\
\hline South 1 & 86 & 111 & 20 & 4 & 1 \\
South 2 & 37 & 23 & 5 & 0 & 0 \\
Middle & 1 & 0 & 0 & 0 & 1 \\
North 1 & 1 & 1 & 0 & 0 & 0 \\
North 2 & 0 & 1 & 0 & 0 & 0 \\
\hline F. lugubris & Forest & Edge & Yard & Meadow & Mire \\
\hline South 1 & 40 & 53 & 6 & 2 & 1 \\
South 2 & 14 & 30 & 4 & 0 & 2 \\
Middle & 12 & 21 & 2 & 0 & 0 \\
North 1 & 18 & 27 & 1 & 1 & 7 \\
North 2 & 10 & 22 & 1 & 1 & 1 \\
\hline F. rufa & Forest & Edge & Yard & Meadow & Mire \\
\hline South 1 & 49 & 98 & 23 & 11 & 1 \\
South 2 & 11 & 28 & 13 & 1 & 0 \\
Middle & 1 & 1 & 0 & 0 & 0 \\
North 1 & 0 & 0 & 0 & 0 & 0 \\
North 2 & 0 & 0 & 0 & 0 & 0 \\
\hline F. pratensis & Forest & Edge & Yard & Meadow & Mire \\
\hline South 1 & 11 & 23 & 2 & 2 & 0 \\
South 2 & 6 & 10 & 0 & 1 & 1 \\
Middle & 0 & 2 & 0 & 0 & 0 \\
North 1 & 0 & 0 & 0 & 0 & 0 \\
North 2 & 0 & 0 & 0 & 0 & 0 \\
\hline & & & & & \\
\hline
\end{tabular}

as southern or whole country species in the Boreal zone in Finland as was done in earlier studies (Baroni Urbani \& Collingwood, 1977; Collingwood, 1979; Punttila \& Kilpeläinen, 2009). This pattern resembles that of the altitudinal distribution of the same species in Central Europe (Vandegehuchte et al., 2017; Seifert, 2018). Formica polyctena, F. rufa and $F$. pratensis are clearly southern species in Finland and lowland species in Central Europe, e.g., Switzerland (Vandegehuchte et al., 2017). However, $F$. polyctena is also recorded in the north but with a very low relative abundance. The Central European high-altitude species, F. aquilonia and F. lugubris, were common through the country, with $F$. lugubris being more common in the north than in the south.

Formica lugubris is a quick colonizer of young and fragmented forests (Punttila, 1996), and is even recorded in small $<0.5$ ha forests (Sorvari, 2018). Its increasing relative abundance in the Middle to North 2 zones may be explained by the low or zero abundance of the monodomous competitors, $F$. rufa and F. pratensis. The forests in the North 2 zone are often sparse and the ground exposed to sun, thus permanently resembling a young succession stage forest. The decrease in the relative abundance of $F$. aquilonia in North 1 and North 2 after a peak in the Middle zone may be due to the competitive pressure of the effective colonizer F. lugubris in those zones.

There is a controversy over the northern distribution of F. polyctena as some authors (Baroni Urbani \& Collingwood, 1977; Collingwood, 1979; Douwes et al., 2012; Seifert, 2018; Stockan et al., 2016) restrict it to southern Finland and some report it in northern Finland (Punttila \& Kilpeläinen, 2009; Czechowski et al., 2012). Punttila \& Kilpeläinen (2009) report an increase in abundance in $F$. polyctena from south to north. However, that data was based on only 12 samples, of which about half were in the area corresponding to zone North 1, and there was no data from a zone that corresponds to North 2 in the present study. In contrast, in the present data with 298 samples, the relative abundance of $F$. polyctena declined quickly from south to north and was almost absent after South 2; 98.3\% of $F$. polyctena records were from zones South 1 and South 2. While F. polyctena still occurs in both North 1 and North 2 with a very low abundance, the decline in relative abundance occurs practically in synchrony with the two other southern lowland species, $F$. rufa and $F$. pratensis.

In this citizen science data set, Formica aquilonia (with $58.1 \%$ relative abundance) was clearly the most abundant species of the five RWAs in Finland. This has clearly been the conclusion of other studies in Finland (e.g., Punttila \& 
Kilpeläinen, 2009). Of the rest, $F$. polyctena, F. lugubris and $F$. rufa form a triplet of species with approximately similar abundances $(11.5-14.3 \%)$ and $F$. pratensis is clearly the least common $(2.8 \%)$.

A recent RWA census in Switzerland with 258 active RWA nests (Vendegehuchte et al., 2017) shows that $F$. lugubris is the most common RWA in Switzerland with an abundance of $54.6 \%$ followed by F. paralugubris Seifert, 1996 (31.8\%), which is absent from Finland. The other species, $F$. polyctena, $F$. rufa and $F$. aquilonia, have relative abundances of $2.3-5.4 \%$. Formica pratensis was not found in that census, which only included forest habitats (Swiss National Forest Inventory).

A recent survey in Bulgaria based on 229 active RWA nests (Antonova \& Marinov, 2021) gives relative abundances of F. lugubris of $44 \%, F$. rufa of $40 \%, F$. pratensis $15 \%$ and hybrid $F$. polyctena X rufa $1 \%$. Although present in Bulgaria, F. aquilonia was not recorded in this survey indicating its rareness in that country. The presence of hybrid F. polyctena $\mathrm{X}$ rufa indicates that there is at least historical evidence of the occurrence of this species in Bulgaria.

Formica lugubris, is a mountain species, which is common in Switzerland and Bulgaria and its relative abundance increases with increase in altitude, which resembles its distribution in the north of Finland; however, unlike in Finland, F. aquilonia and F. polyctena are rare or absent in Switzerland and Bulgaria. Formica rufa is generally a southern species (e.g., Czechowski et al., 2012) and is commoner in Bulgaria than in Finland and Switzerland. Finally, F. pratensis is relatively rare in all the three countries and was not recorded in the Swiss census.

A possible limitation of this kind of citizen science data could be that people may find large nests easier to locate than small ones. As $F$. polyctena and $F$. aquilonia build larger nests than the other Finnish RWAs (e.g., Punttila \& Kilpeläinen, 2009), those species may be slightly overrepresented in the data. However, this possible error is absent or rather negligible in analyses of each species' relative abundance in each of the latitudinal zones. Similarly, national forest inventory-based censuses may have the same limitation as small nests may not be found; in addition, census grids may be preselected based on criteria that can be suboptimal for a RWA census.

\section{Habitat preference}

In the case of RWAs, preference for forest habitats are naturally high. Here, 79-92\% of the species samples came from forests and forest edges. The most forest-specialist species is $F$. aquilonia and the least is $F$. rufa (combined forest and forest edge of $92.4 \%$ and $79.3 \%$, respectively). Surprisingly, the meadow wood ant $F$. pratensis is the second most forest dwelling species $(89.6 \%)$, however, it has a higher preference for forest edges than for forests $(60.3 \%$ vs. $29.3 \%$ ). Based on the current data, F. rufa may be the most tolerant of living close to buildings as its relative abundance in yards $(15.2 \%)$ is much higher than that of the other species.

The polydomous species pair $F$. aquilonia and $F$. polycte$n a$ did not differ in their habitat preference. Thus, the dif- ference in the present data between the species is mainly due to different abundance and geographical distribution patterns. Among the three monodomous species, forests and mires are more common habitats for F. lugubris than for the others, forest edges are more common for F. pratensis and yards more common for F. rufa than for the others. Meadows are less common habitats for F. lugubris than for F. pratensis and F. rufa.

Finland, Switzerland and Bulgaria have different forest habitat specialist species of RWA: F. aquilonia in Finland, F. lugubris in Switzerland (Vendegehuchte et al., 2017) and F. rufa in Bulgaria (Antonova \& Marinov, 2021). Interestingly, $F$. rufa, which is a shade tolerant species in Bulgaria is the least inside forest-dweller in Finland. Formica pratensis is quite intolerant of canopy closure in Bulgaria (Antonova \& Marinov, 2021) but is frequently recorded in the interiors of forests by citizen scientists in Finland. Nests of this species are often recorded in relatively young forests with low shading and sun exposed parts in older forest just a few meters from the edge of a forest (own observations). The citizen science instructions were as simple as possible, thus, nests located in such places are likely to be classed as in Forests.

There is some level of uncertainty in habitat preference since many of the citizen scientists might have biased their sampling towards forest habitats, forests and forest edges since they were looking for wood ant mounds. As citizens of a forested country, Finnish people might have a search image of large mounds in forests and forest edges. In addition, their previous knowledge of a mound nest in their yard may have increased the percentage of yard nests. Due to this possible search image, meadows and mires might be underrepresented. In addition, there are possibly some cases labelled as 'Yard' that actually could have been labelled as 'Forest edge' in cases where the nest is on the edge between yard and forest.

On the other hand, systematic censuses as a part of national forest inventories may have sampling grids that are preselected to occur in forest habitats; thus, possibly leaving out intermediate zones between forests and open nonforested habitats that could be key habitats for such RWA species as F. pratensis. Such habitats can be inhabited by all other RWA species as well if there is a shortage of trees.

\section{CONCLUSION}

The distribution of the RWAs along the latitudinal gradient in the north of Finland resembles that of their distribution along an altitudinal gradient in the Alps in Central Europe, except for the highland/northern species, which are also present in the south of Finland and in the lowlands.

The nationwide data obtained on the distributions and relative abundances from all over the country is the first of its kind in Finland. The data will be kept for future comparisons with similar surveys to detect changes in species distributions, relative abundances and habitat preference. Nation-wide RWA censuses across Europe would produce quantitative data that is essential for evaluating the species specific conservation status of these keystone species. 
However, the weaknesses of citizen science and forest inventory data should be resolved or at least minimised.

ACKNOWLEDGEMENTS. I am grateful for the over 1,000 Finns who collected the specimens and gave me an opportunity to share our experiences with ants. Also, I am grateful to three anonymous reviewers for their improving comments and suggestions. The English language was checked by a professional, native English speaker from Lingsoft (Turku, Finland). The study was funded by a grant from the Kuopio Naturalists Society KLYY.

\section{REFERENCES}

Antonova V. \& Marinov M.P. 2021: Red wood ants in Bulgaria: distribution and density related to habitat characteristics. - J. Hymenopt. Res. 85: 135-159.

Baroni Urbani C. \& Collingwood C.A. 1977: The zoogeography of ants (Hymenoptera, Formicidae) in northern Europe. Acta Zool. Fenn. 152: 2-34.

Collingwood C.A. 1979: The Formicidae (Hymenoptera) of Fennoscandia and Denmark. - Fauna Entomol. Scand. 8: 1-174.

Czechowski W. 1996: Colonies of hybrids and mixed colonies; interspecific nest takeover in wood ants (Hymenoptera, Formicidae). - Memorabilia Zool. 50: 1-115.

Czechowski W., Radchenko A., Czechowska W. \& VepsäläInen K. 2012: The Ants of Poland with References to the Myrmecofauna of Europe. Fauna Poloniae, Natura optima dux Foundation, Warszava, $496 \mathrm{pp}$.

Domisch T., Risch A.C. \& Robinson E.J.H. 2016: Wood ant foraging and mutualism with aphids. In Stockan J.A. \& Robinson E.J.H. (eds): Wood Ant Ecology and Conservation. Cambridge University Press, Cambridge, UK, pp. 145-176.

Douwes P., Abenius J., Cederberg B., Wahlstedt U., Hall K., Starkenberg M., ReIsborg C. \& Östman T. 2012: National Key to Swedish Flora and Fauna. Steaks: Ant - Wasps: Hymenoptera: Formicidae - Vespidae. ArtDatabanken, SLU, Uppsala, 382 pp. [in Swedish].

Frouz J., Jílková V. \& Sorvari J. 2016: Contribution of wood ants to nutrient cycling and ecosystem function. In Stockan J.A. \& Robinson E.J.H. (eds): Wood Ant Ecology and Conservation. Cambridge University Press, Cambridge, UK, pp. 207-220.

Goropashnaya A.V., Fedorov V.B. \& Pamilo P. 2004: Recent speciation in the Formica rufa group ants (Hymenoptera, Formicidae): Inference from mitochondrial DNA phylogeny. - Mol. Phylogen. Evol. 32: 198-206.

Goropashnaya A.V., Fedorov V.B., Seifert B. \& Pamilo P. 2012: Phylogenetic relationships of palearctic Formica species (Hymenoptera, Formicidae) based on mitochondrial cytochrome $b$ sequences. - PLoS ONE 7: e41697, 7 pp.

Kulmuni J., Seifert B. \& Pamilo P. 2010: Segregation distortion causes large-scale differences between male and female genomes in hybrid ants. - Proc. Natl. Acad. Sci. U.S.A. 107: 7371-7376.
LENOIR L. 2003: Response of the foraging behaviour of red wood ants (Formica rufa group) to exclusion from trees. - Agric. For. Entomol. 5: 183-189.

Paukkunen J., Paappanen J., Leinonen R., Punttila P., Pöyry J., Raekunnas M., Teräs I., VepsäläInen K. \& Vikberg V. 2019: Stinging wasps, bees and ants, Aculeata. In Hyvärinen E., Juslén A., Kemppainen E., Uddström A. \& Liukko U.-M. (eds): The 2019 Red List of Finnish Species. Ministry of the Environment \& Finnish Environment Institute, Helsinki, pp. 451-465.

PuntTILA P. 1996: Succession, forest fragmentation, and the distribution of wood ants. - Oikos 75: 291-298.

Punttila P. \& KilpeläInen J. 2009: Distribution of mound-building and species (Formica spp., Hymenoptera) in Finland: preliminary results of a national survey. - Ann. Zool. Fenn. 46: $1-15$.

Robinson E.J.H., Stockan J.A. \& Iaison G.R. 2016: Wood ants and their interaction with other organisms. In Stockan J.A. \& Robinson E.J.H. (eds): Wood Ant Ecology and Conservation. Cambridge University Press, Cambridge, UK, pp. 177-206.

Social Insects Specialist Group 1996: Formica rufa. The IUCN Red List of Threatened Species 1996: e.T8645A12924924. URL: https://dx.doi.org/10.2305/IUCN.UK.1996.RLTS. T8645A12924924.en (last accessed 25 Aug. 2021).

SORVARI J. 2006: Two distinct morphs in Formica polyctena in Finland: a result of hybridization? - Entomol. Fenn. 17: 1-7.

SORVARI J. 2018: Wood ant assemblages of Formica rufa group on lake islands and in mainland woodland in Central Finland. Entomol. Fenn. 29: 21-29.

SORVARI J. 2021: Distribution of Finnish mound-building Formica ants (Hymenoptera: Formicidae) based on using a citizen science approach. - Eur. J. Entomol. 118: 57-62.

SORVARI J. \& HAKKARAINEN H. 2007: Wood ants are wood ants: deforestation causes population declines in the polydomous wood ant Formica aquilonia. - Ecol. Entomol. 32: 707-711.

Sorvari J., HaAtanen M.-K. \& Vesterlund S.-R. 2011: Combined effects of overwintering temperature and habitat degradation on the survival of boreal wood ant. - J. Insect Conserv. 15: 727-731.

SORVARI J., Elo R.A. \& HÄRKÖNEN S.K. 2016: Forest-built nest mounds of red wood ant Formica aquilonia are no good in clear fells. - Appl. Soil Ecol. 101: 101-106.

Stockan J.A., Robinson E.J.H., Trager J.C., Yao I. \& Seifert B. 2016: Introducing wood ants: evolution, phylogeny, identification and distribution. In Stockan J.A. \& Robinson E.J.H. (eds): Wood Ant Ecology and Conservation. Cambridge University Press, Cambridge, UK, pp. 1-2.

VaAhtera E. 2019: Silviculture. In Peltola A. (ed.): Finnish Forest Statistics. Luonnonvarakeskus, Helsinki, pp. 59-76.

Vandegehuchte M.L., Wermelinger B., Fraefel M., Baltensweiler A., Düggelin C., Brändli U.-B., Freitag A., BernasCONI C., Cherix D. \& Risch A.C. 2017: Distribution and habitat requirements of red wood ants in Switzerland: Implications for conservation. - Biol. Conserv. 212: 366-375.

Received September 3, 2021; revised and accepted January 17, 2022 Published online February 1, 2022 